\title{
Developmental surveillance of young children in clinical settings: Time to step out or step up?
}

\author{
John C. LeBlanc MD MSc, Robin Williams MD
}

Cite as: CMAJ 2017 May 23;189:E709-10. doi: 10.1503/cmaj.161182

See related article at www.cmajopen.ca/lookup/doi/10.9778/cmajo.20140121

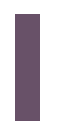
n 2015, the Canadian Task Force on Preventive Health Care recommended against screening for developmental delay using standardized tools in children aged one to four years who have no apparent signs of developmental delay and whose parents are not concerned about them. ${ }^{1}$ The Canadian Paediatric Society is concerned that the task force recommendation may lead to reduced monitoring of children's development because of the failure among many policy-makers and clinicians to distinguish screening, which the statement addresses, from developmental surveillance, which the statement carefully excludes. Routine screening for developmental delay is not the same as developmental surveillance, which is a broader, flexible, ongoing assessment of development that physicians must continue to do.

Clinicians monitor development in childhood because early intervention for developmentally delayed children makes a difference. Studies that assess adult status of developmentally delayed and disadvantaged participants in the HighScope Perry ${ }^{2}$ and Abecedarian ${ }^{3}$ randomized controlled trials have shown the following: early intervention for these children leads to better literacy skills that persist into secondary school, higher graduation rates, lower risk of adult unemployment and lower rates of criminal convictions. The challenge is translating lessons from such experiments into public health and clinical settings where the practitioner must identify the small proportion of children with an undetected delay that could benefit from an intervention.

The task force assessed standardized screening that embodies the following principles: ${ }^{4}$ the condition must have an important burden of illness and its natural course must be understood. There needs to be a preclinical marker that can be detected by a screening program and that can be exploited by an intervention to improve outcomes. Finally, the screening program must be affordable and acceptable. Some childhood screening programs (e.g., metabolic diseases in neonates) easily fulfill these criteria.

Applying these criteria to developmental delay has substantial limitations. First, "developmental delay" is an umbrella term, similar to cancer. It is a common manifestation of many discrete underlying disorders that lead to specific delays in speech, behaviour, and gross and fine motor problems, with each disorder having its own natural course, preclinical markers and potential

\section{KEY POINTS}

- To date, no screening protocol has been shown to detect and improve developmental outcomes for children aged one to four with unsuspected developmental delay.

- A recent recommendation by the Canadian Task Force on Preventive Health Care to not screen for developmental delay in children aged one to four should not apply to developmental surveillance, which is a broad, flexible, ongoing process of monitoring development in young children in their clinical and social context, which also involves parents or caregivers.

- High-quality research is needed to develop effective and efficient screening and developmental surveillance strategies.

interventions. Second, developmental delays are not the preclinical disease states typically sought by screening practices, such as an abnormal blood test or tissue sample; the marker (i.e., developmental delay) is itself the condition of interest and meaningful to both clinicians and families. Third, developmental delay is, by definition, a rate of change of normal markers, not the presence of an abnormal and usually occult marker at a particular point in time. An effective screening strategy must therefore detect the flattened slope of a developmental trajectory curve compared with a reference curve, rather than the position at a single or particular point.

Traditional screening manoeuvres have defined pathways to be followed once an abnormal marker is found. On the other hand, a clinician faced with a mild delay in speech or motor milestones in a child is free to decide whether to act immediately or schedule a follow-up visit a few weeks or months later. That visit can be used to assess if the previously detected delay is transient or ongoing (i.e., is either an upgoing or flattened trajectory slope, as measured over at least two time points). Most studies cited in the task force report used a screening strategy that relied on a single assessment and therefore did not capture the dynamic aspect of development. Finally, typical interventions to alter developmental trajectories - such as early intensive behavioural intervention or speech and language therapy - take place over 
months and require follow-up over several years to show benefit. It is not surprising, then, that the task force concluded there was a paucity of evidence either for or against screening for developmental delay.

Developmental surveillance refers to a broader, more flexible, ongoing assessment of development that involves practitioners and parents and takes note of the child's environment. ${ }^{5}$ The task force recommendation has implications for public health nurses, family physicians and pediatricians who care for preschool children because of a long-standing emphasis on monitoring neurodevelopment by the College of Family Physicians of Canada, the Canadian Paediatric Society and the American Academy of Pediatrics. $^{2,6,7}$ The Canadian Paediatric Society and the College of Family Physicians of Canada have collaborated to ensure that developmental surveillance is an integral part of primary care practice for young children and should occur at each visit. They also promote the Rourke Baby Record ${ }^{8}$ as a tool to help practitioners note developmental status and discuss it with parents or caregivers. If clinicians and policy-makers apply the task force recommendation against screening to developmental surveillance, and therefore stop paying attention to development, some children will come to harm. ${ }^{9}$

The task force chose to make its Grading of Recommendations, Assessment, Development and Evaluation (GRADE) recommendation against screening 10 "strong" rather than "weak," based on the paucity of evidence in support of screening, but stating its confidence that harm would result due to false-positives and unnecessary resources allocated to detecting children with developmental delay and generating unnecessary referrals. The difficulty with the "strong" recommendation was that no evidence was cited showing harm from false-positives or unnecessary resource use and most clinical activity and parent interaction is already occurring because of developmental surveillance.

Although recommending strongly against screening, the task force states that "studies evaluating the best ways to treat children with known developmental delay should be an urgent priority." It also identifies the need for high-quality studies of the "most effective methods for surveillance of developmental milestones or case finding." We wholeheartedly agree with these recommendations and call for high-quality cohort studies or randomized controlled trials of formal screening in conditions where there is a possibility of detecting a preclinical or subtle early sign that would allow for earlier introduction of an effective intervention (e.g., subtle or new preclinical markers of autism spectrum disorders).

The impact of developmental surveillance also has not been sufficiently examined. A tool such as the Rourke Baby Record must be considered a "best practice" that is ultimately derived by expert opinion plus evidence-based interventions (e.g., vitamin D supplementation for breastfed infants) when they exist. There is still no evidence, for or against, that addresses whether physicians who implement the Rourke Baby Record alter the developmental trajectories of their young patients compared with physicians who do not do so. Until that evidence emerges, primary care clinicians should no more be asked to abandon developmental surveillance than to abandon other "best practices" with insufficient evidence, such as the number and content of prenatal visits.

\section{References}

1. Warren R, Kenny M, Bennett T, et al. Screening for developmental delay among children aged 1-4 years: a systematic review. CMAJ Open 2016;4:E20-7.

2. Schweinhart LJ, Montie J, Xiang Z, et al. Lifetime effects: the HighScope Perry preschool study through age 40. Ypsilanti (MI): HighScope Press; 2005.

3. Campbell FA, Pungello EP, Burchinal M, et al. Adult outcomes as a function of an early childhood educational program: an Abecedarian Project follow-up. Dev Psychol 2012;48:1033-43.

4. Wilson JMG, Jungner G. Principles of screening for disease. Geneva: World Health Organization; 1968. Available: http://apps.who.int/iris/bitstream/10665/37650/17/ WHO_PHP_34.pdf (accessed 2017 Feb. 16).

5. Final report to the OCFP for the evidence to support the 18 month well baby visit. Toronto: Ontario College of Family Physicians; 2006. Available: http://ocfp.on.ca/ docs/cme/final-report-for-the-evidence-to-support-the-18-month-well-baby-visit-. pdf (accessed 2017 Feb. 16)

6. Rourke L, Leduc D. Improving the odds for effective developmental surveillance. Paediatr Child Health 2012;17:539-40.

7. Jenco M. Academy stands by its screening recommendations. AAP News 2015. Available: www.aappublications.org/content/early/2015/07/07/aapnews.20150707-1 (accessed 2017 Feb. 16).

8. Riverin B, Li P, Rourke L, et al. Rourke Baby Record 2014: evidence-based tool for the health of infants and children from birth to age 5. Can Fam Physician 2015; 61:949-55.

9. LeBlanc JC, Belanger SA, Andrews D, et al. Take home message of Task Force report: NOT the strong recommendation against developmental screening, BUT the need for rigorous research and practice [letter]. CMAJ Open 2016 June 10 [Epub ahead of print]. doi:10.1503/cmaj.151437.

10. Brozek JL, Akl EA, Alonso-Coello P, et al.; GRADE Working Group. Grading quality of evidence and strength of recommendations in clinical practice guidelines. Part 1 of 3 . An overview of the GRADE approach and grading quality of evidence about interventions. Allergy 2009;64:669-77.

\section{Competing interests: None declared.}

Affiliations: Departments of Pediatrics, Community Health and Epidemiology, and Psychiatry (LeBlanc), Dalhousie University; IWK Health Centre (LeBlanc), Halifax, NS; Canadian Paediatric Society (Foster), Ottawa, Ont.

This article has been peer reviewed.

Correspondence to: John LeBlanc, John.LeBlanc@Dal.ca 